\title{
Antiangiogenic agents after first line and sorafenib plus chemoembolization: a systematic review
}

\author{
Andrea Casadei Gardini ${ }^{1}$, Daniele Santini ${ }^{2}$, Giuseppe Aprile ${ }^{3}$, Nicola Silvestris ${ }^{4}$, \\ Emanuele Felli ${ }^{5}$, Francesco Giuseppe Foschi ${ }^{6}$, Giorgio Ercolani ${ }^{7,8}$, Giorgia Marisi ${ }^{9}$, \\ Martina Valgiusti ${ }^{1}$, Alessandro Passardi ${ }^{1}$, Marco Puzzoni ${ }^{10}$, Marianna Silletta ${ }^{2}$, \\ Oronzo Brunetti ${ }^{4}$ Giovanni Gerardo Cardellino ${ }^{3}$, Giovanni Luca Frassineti ${ }^{1}$ and \\ Mario Scartozzi ${ }^{10}$

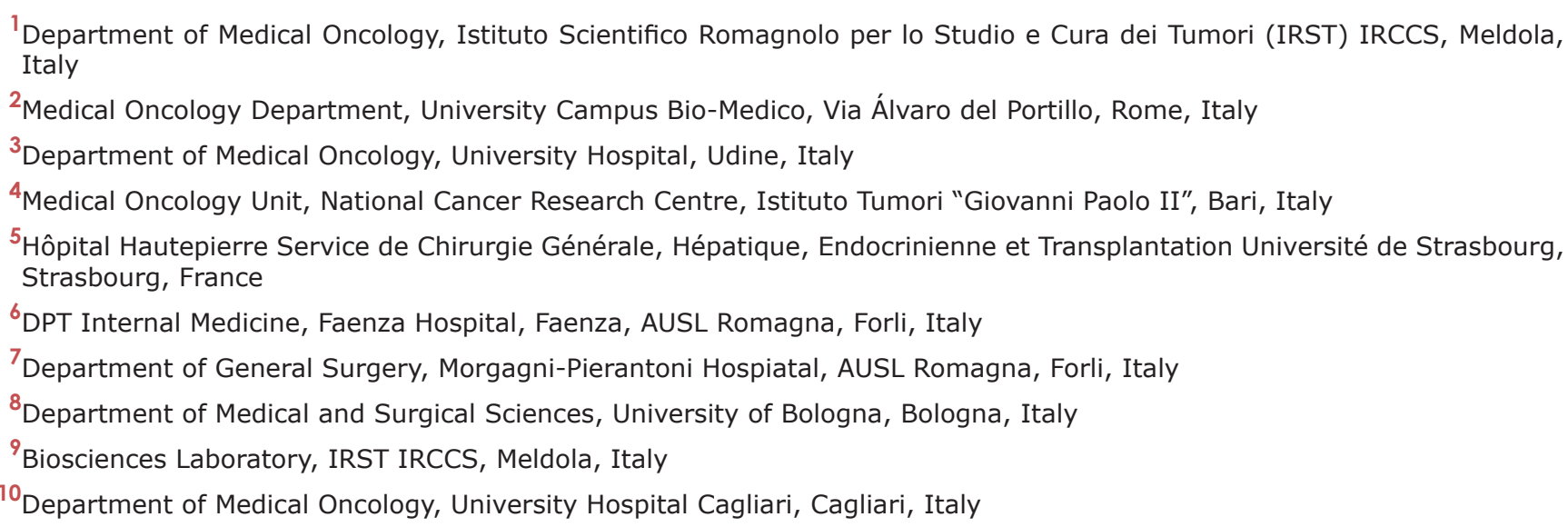 \\ Correspondence to: Andrea Casadei Gardini, email: andrea.casadei@irst.emr.it \\ Keywords: hepatocellular carcinoma, tace, antiangiogenic, second line, transcatheter arterial chemoembolization \\ Received: November 22, $2016 \quad$ Accepted: April 27, $2017 \quad$ Published: July 22, 2017
}

Copyright: Gardini et al. This is an open-access article distributed under the terms of the Creative Commons Attribution License 3.0 (CC BY 3.0), which permits unrestricted use, distribution, and reproduction in any medium, provided the original author and source are credited.

\section{ABSTRACT}

Transarterial chemoembolization (TACE) is the standard treatment for intermediate stage, although the combination of TACE with sorafenib may theoretically benefit HCC patients in intermediate stage. Owing to the significant antiangiogenic effect of sorafenib and the limitation of TACE, it is rational to combine them. Though the strategy of combining TACE and sorafenib has been increasingly used in patients with unresectable HCC but the current evidence is controversial and its clinical role has not been determined yet.

In first-line therapy, patients receiving sorafenib had increased overall survival and progression free survival. Therefore several antiangiogenic agents have entered clinical studies on HCC, many with negative results. This review discusses the current drug development for patients with HCC and role of TACE plus sorafenib.

\section{INTRODUCTION}

Hepatocellular carcinoma (HCC) is the sixth cause of cancer in the world [1].

TACE is the best treatment of intermediate stage in $\mathrm{HCC}$ in Europe and the United States [1-2] but in many Asian countries it's also used in selected cases of advanced disease [3-6].
Despite high local disease control rate and the possibility to improve patients' survival, TACE is considered a palliative procedure $[7,8]$.

Hypoxia caused by TACE can leads to the local release of angiogenic growth factors, this release may contribute to tumor recurrence or metastases and poor outcome [9-12]. 


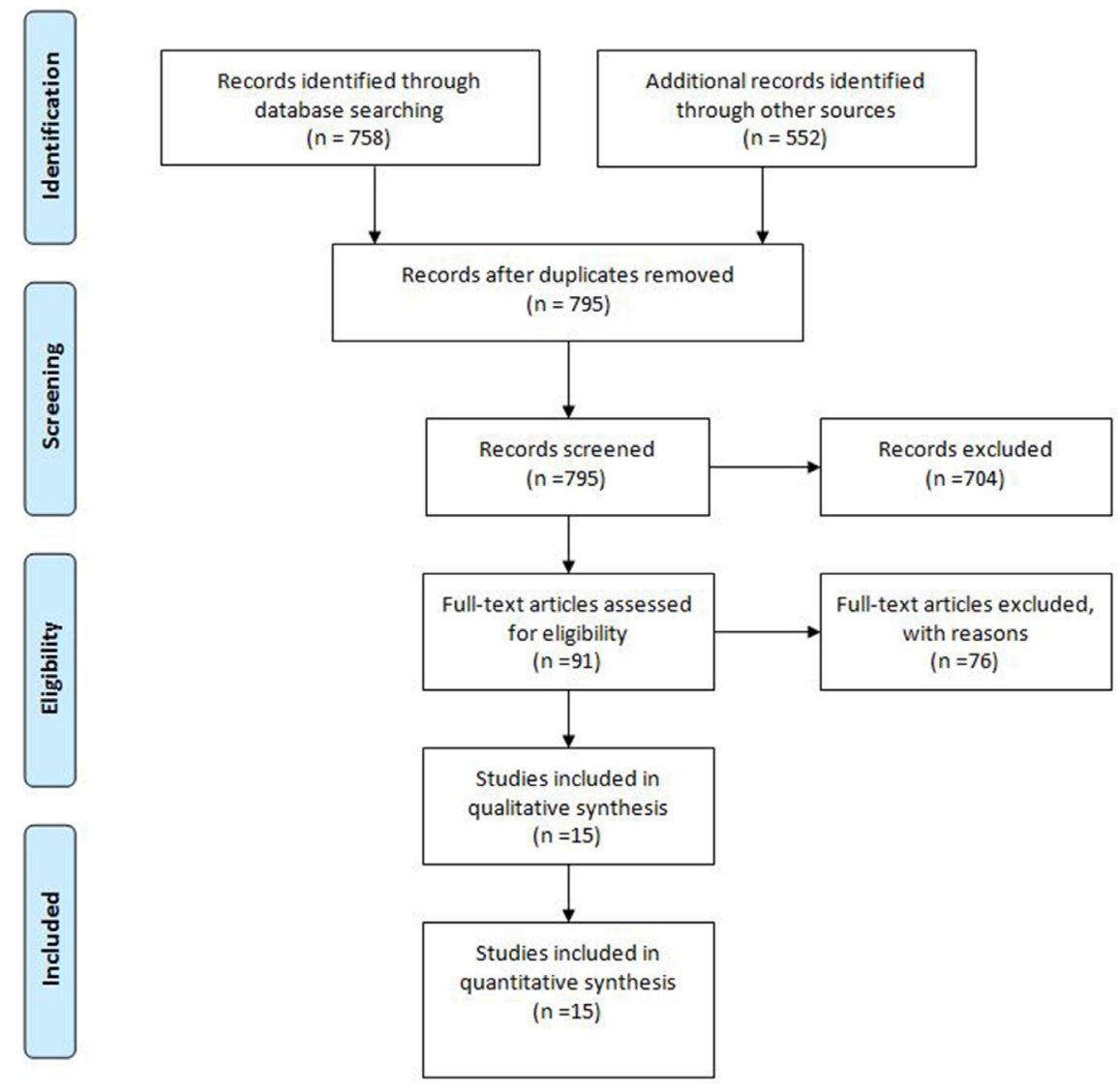

Figure 1: PRISMA guidelines of TACE plus Sorafenib.

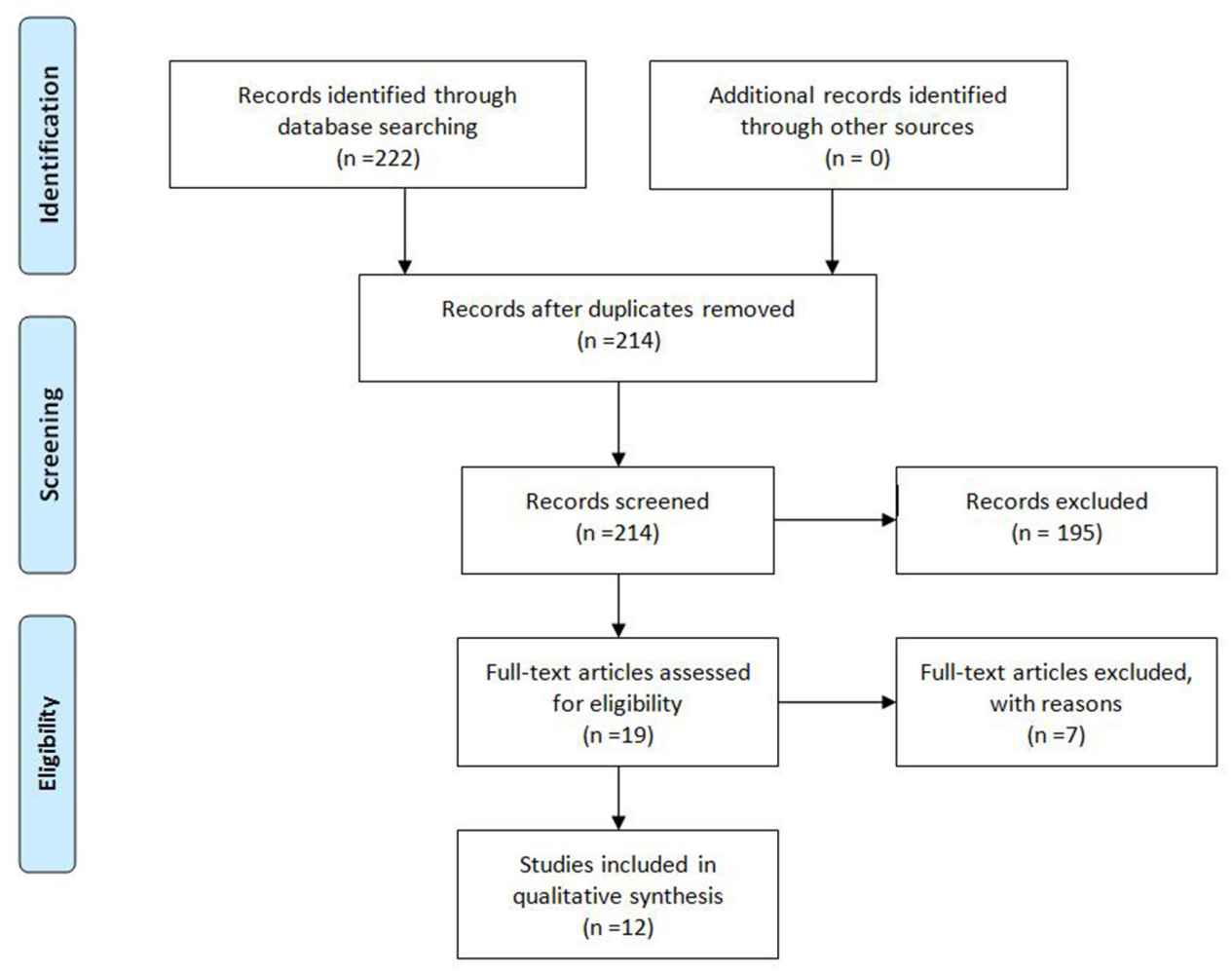

Figure 2: PRISMA guidelines of antiangiogenic agents after Sorafenib. 
Table 1: summarizes the main studies of sorafenib plus TACE

\begin{tabular}{lll}
\hline & Trial name/PI & Results \\
\hline PHASE III & SPACE Trial & mTTP: (S) $169 \mathrm{~d}$ vs. (P) $166 \mathrm{~d} \mathrm{p}<0.072$ \\
& Kudo & mTTP: (S) $5.4 \mathrm{~m} \mathrm{vs.} \mathrm{(P)} 3.7 \mathrm{~m} \mathrm{p}<0.252$ \\
& Sansonno & mTTP: (S) $9.2 \mathrm{~m}$ vs. (P) $4.9 \mathrm{~m} \mathrm{p}<0.001$ \\
PHASE II & Hofmann & mTTP: (S) 125 day vs. (P) $171 \mathrm{day} \mathrm{m}$ \\
& START Trial & p=0.005 \\
& SOCRATES Trial & mTTP: $9 \mathrm{~m} \mathrm{ORR:} 53.8 \%$ \\
& COTSUN Trial & mTTP: $16.4 \mathrm{~m}$ \\
\end{tabular}

mTTP: median time to progression; d: days; m: months; (S): sorafenib; (P): placebo; ORR: overall response rate.

Table 2: Table 2 drugs on trial and results

\begin{tabular}{lcl}
\hline Drug & Phase Study & Results \\
\hline Regorafenib & III & mPFS: 3,1 months \\
mOS: 10,6 months \\
Bevacizumab & II & mPFS: 6,9 months \\
Beva + gemox & II & mOS: 12.4 months \\
Sunitinib & III & mOS: 15.0 months \\
Sunitinib vs sorafenib & III & mOS:9,8 months \\
Brivanib & II & mOS: 7,9 months vs. 10.2 months \\
BRISK-PS (Brivanib vs. placebo) & III & mOS: 9.7 months \\
BRISK-FL (brivanib vs placebo) & III & mOS: 9.4 months vs. 8.3 months \\
Pazopanib & I & mOS: 9.4 months vs. 8.3 months \\
Tivantinib & & mTTP: 4.5 months \\
Dovitinib (dovitinib vs sorafenib) & II & mOS: 7.2 months vs. 3.8 months in \\
\hline
\end{tabular}

Sorafenib acts through inhibition of vascular and endothelial growth factor receptor 2 and 3 and plateletderived growth factor receptor beta leading to an antiangiogenic effect. Molecular predictors of sorafenib efficacy have not yet been identified [13-17].

Therefore, the combination of TACE with sorafenib may theoretically benefit HCC patients.

Currently, sorafenib has been shown to significantly increase overall survival (OS) and progression free survival (PFS) in patients with BCLC stage C.
Hepatocellular carcinoma are vascular tumours and inhibition of angiogenesis may be represent a potential therapeutic target. For this reason, several antiangiogenic agents have studies on HCC.

This review discusses the current drug development for patients with HCC and the combination of TACE plus sorafenib. 


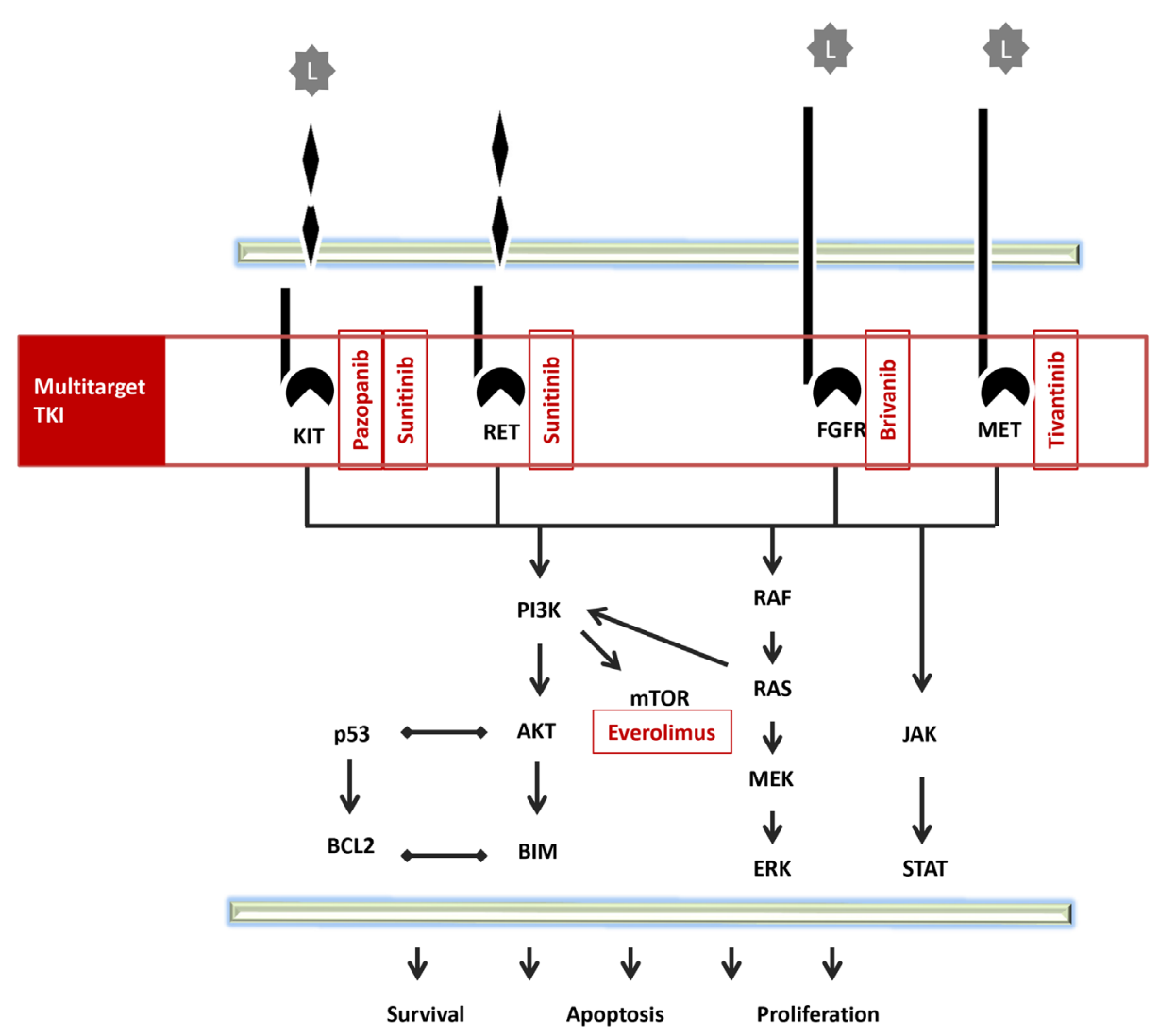

Figure 3: Pathway of multitarget TKI.

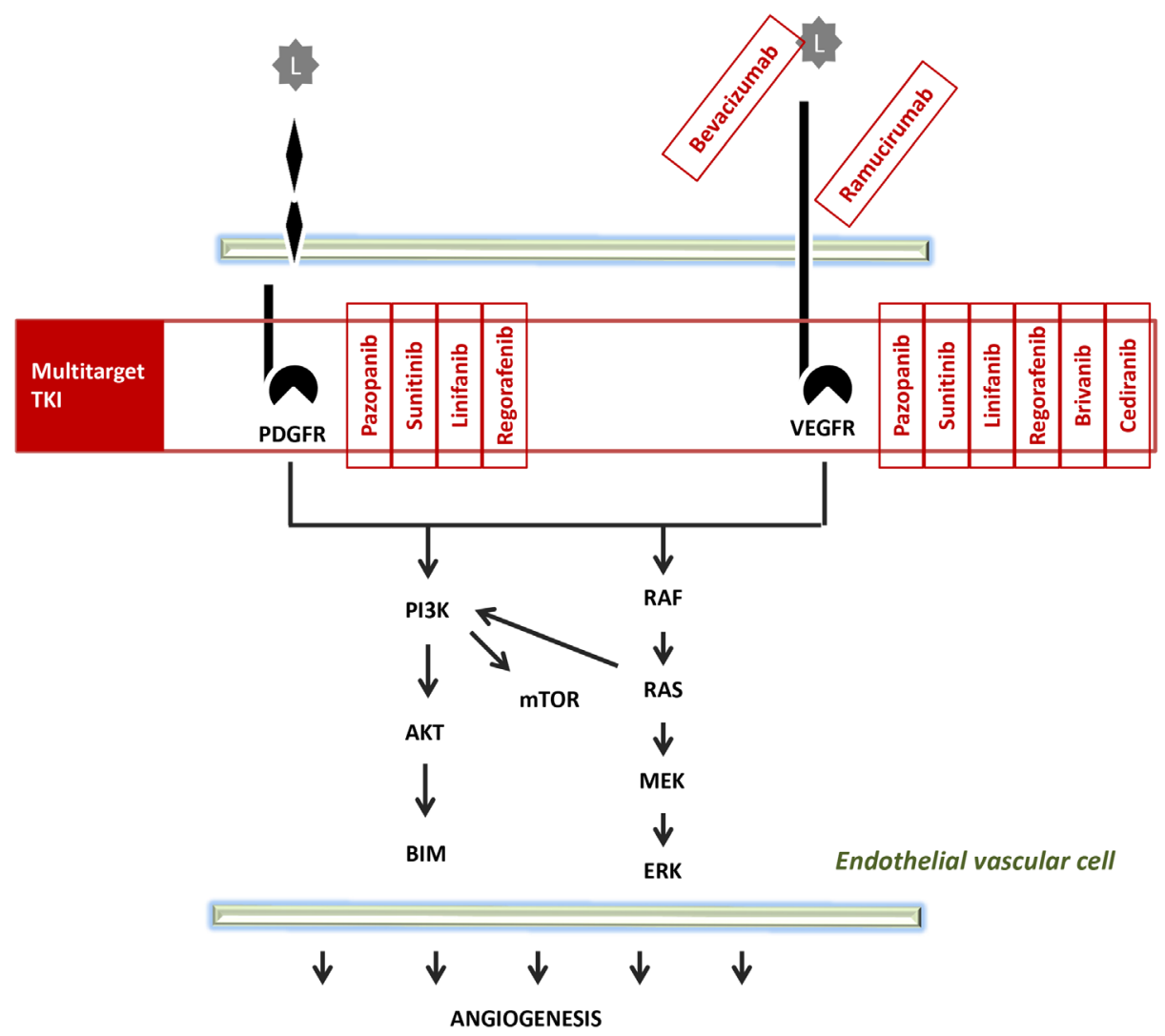

Figure 4: Pathway of multitarget TKI. 


\section{MATERIALS AND METHODS}

\section{Search strategy and selection criteria}

We searched on PubMed/MEDLINE and Clinicaltrials.gov using the following keywords: "secondline AND hepatocellular carcinoma" for antiangiogenic study in second line and "TACE plus Sorafenib" or "TACE and Sorafenib" for sorafenib plus TACE. We use PRISMA guidelines (Figures 1 and 2) to identify all study.

We reviewed the references of all included articles to identify additional sources of data, missing articles or meeting abstracts. When multiple sources of data from the same study population were found, we relied on the data from the most complete peer-reviewed publication.

\section{Sorafenib plus tace}

Several studies have explored this combination therapy, from either retrospective series or small earlyphase studies. Moreover there is a wide heterogeneity in study design especially in underlying liver disease (HCV vs HBV), overall hepatic function (Child A vs Child B), BCLC stage (A vs B vs C), modality of sorafenib treatment (sequential vs. continuous vs. interrupted), and variables linked to TACE treatment.

Table 1 summarizes the main studies of sorafenib plus TACE.

According to the classification by Strebel et al [18], trials that encourage combination of TACE with sorafenib are divided into three main categories:

1. continuous schedule: patients are treated all the time with sorafenib.

2. Interrupted schedule: patients are treated with sorafenib only between TACE sessions.

3. Sequential schedule: the patients was treated with TACE followed by sorafenib.

\section{Randomized trial}

In literature there are four randomized trial.

The SPACE trial, is a phase II randomized trial that enrolled 307 patients [19]. Even if the primary endpoint was no achieved $(p=0.072)$, in fact the time to progression was similar between two groups (169 days for sorafenib group respect166 days for placebo group). The HR for overall survival was 0.898 .

Kudo et al presented a double blind placebo controlled phase III trial. The trial was designed before the indication of sorafenib in first line of advanced HCC [20]. The study enrolled 458 patients. The study failed the primary endpoint, the median time to progression was of 5.4 in the sorafenib group and 3.7 months in placebo group $(p=0.252)$. Probably, these results may be due to the fact that $91 \%$ had dose interruptions and $73 \%$ of patients had sorafenib dose reductions.
Sansonno et al, in a Italian single-center randomized study enrolled 62 patients [21]. Patients received sorafenib or placebo after conventional TACE. The trial was positive with a median time to progression of 9.2 months in the sorafenib group vs 4.9 months in the placebo group $(\mathrm{p}<$ 0.001).

In the study of Hofmann et al [22], fifty patients were randomly in double-blinded and treated with TACE plus Sorafenib or placebo. The trial was negative, the HR of time to progression was 1.106 (95\% CI: $0.387,3.162)$. The results was negative also for objective response rate, disease control rate, progression free survival and time to liver-transplant.

Recently, a meta-analysis that included all four studies show that TACE plus sorafenib may have superiority of TACE only in terms of time to progression $(\mathrm{HR}=0.77$, $\mathrm{P}=0.005)$ but not for $\mathrm{OS}(\mathrm{HR}=0.97, \mathrm{P}=0.828)$, ORR $(\mathrm{RR}=1.20, \mathrm{P}=0.257)$ and $\mathrm{DCR}(\mathrm{RR}=1.04, \mathrm{P}=0.568)[23]$.

\section{Phase II trial}

START trial [24] enrolled 192 Asian patients. $81.2 \%$ of patients were with HBV. Patients received sorafenib with interrupted schedule (3 days before and after conventional TACE). 52 patients had grade 3/4 adverse events, only $8.1 \%$ discontinued sorafenib for toxicities with no treatment-related deaths. Median time to progression was 9 months with a $53.8 \%$ of response rate.

SOCRATES trial [25], a multicenter single-arm trial enrolled 43 patients. Median overall survival was 20.1 months with time to progression was 16.4 months. The authors value with EASL criteria the response and showed $74,4 \%$ of disease control rate.

COTSUN trial [26], a single-arm enrolled 50 patients with interrupted schedule with median time to progression was 7.1 months, many patients have discontinued sorafenib for thrombocytopenia and skin toxicity.

Another phase II study enrolled 35 patients [27]. The study reported disease control rate of $95 \%$ according to RECIST criteria with 40 dose interruptions and 25 dose reductions for sorafenib. In the paper the authors did not report the data of time to progression, progression free survival or overall survival.

\section{Ongoing study}

The SELECT trial [28] is an ongoing prospective multicenter randomized study. Aims of the study was to evaluate efficacy and safety of continued schedule of sorafenib combined with conventional TACE.

The second trial is a phase III randomized trial $[29,30]$ with intermediate HCC and Child-Pugh score A-B7 with continued schedule. The primary endpoint is progression free survival, secondary endpoints are overall survival and pattern of treatment failure (extrahepatic vs intrahepatic). 
The last is an ongoing phase IV non-randomized study [31] that evaluating the benefits of traditional TACE plus sequential sorafenib with sequential schedule (sorafenib started 2-4 weeks after) versus TACE alone in this setting of patients with child-Pugh score A. The primary endpoint is overall survival and secondary endpoint is time to progression.

\section{Antiangiogenic agents after sorafenib}

Several antiangiogenic agents have entered clinical studies in HCC as summarized in Table 2, in Figures 3 and 4 show the pattern of new drug.

\section{Regorafenib}

Regorafenib show that can be improved overall survival in HCC patients in the RESORCE trial [32].

In the RESORCE trial a total of 573 patients were randomized (patients were randomized 2:1 to receive regorafenib or placebo) after failure of first line with sorafenib. Regorafenib reduce $38 \%$ in the risk of death $(\mathrm{p}<0.001)$ and median overall survival was 10.6 months in patients treated with regorafenib versus 7.8 months in patients treated with placebo. Regorafenib reduced by $54 \%$ the risk of progression or death with median progression free survival of the patients treated with regorafenib was 3.1 vs 1.5 months for patients treatment with placebo (time to progression was 3.2 vs 1.5 respectivily). Disease controll rate was $65.2 \%$ for regorafenib vs $36.1 \%$ for placebo $(\mathrm{p}<0.001)$.

Actualy regorafenib in second line after progression of Sorafenib is the standard of care.

\section{Bevacizumab}

Several studies have explored the use of bevacizumab as a single agent or in combination with other agents.

Bevacizumab was tested in two study as a single agent. In the first study published by Siegel et al [33], the median progression free survival was 6.9 months and median overall survival was 12.4 months. In the second study [34] 13.9\% patients on 43 had partial response and $42 \%$ had disease control rate at 16 weeks.

Bevacizumab was tested in combination with erlotinib in two phase II studies [35, 36].

Kaseb et al. [35] enrolled 59 patients. $24 \%$ achieved partial response, $56 \%$ had stable disease, $10 \%$ progressed (overall survival was 13.7 months and PFS was 7.2 months). In the second study Yau et al [36] enrolled 10 patients with median time to progression of 1.81 months and overall survival was 4.37 months.

In conclusion, these studies demonstrated evidence of antitumor activity of Bevacizumab in HCC. Future prospective studies will tell us the real effectiveness of this drug.

\section{Sunitinib}

Cheng et al. [37] completed a randomized phase III trial comparing sunitinib with sorafenib.

1,074 patients were randomized with median overall survival of 7.9 in the sunitinib arm vs. 10.2 months in the sorafenib arm $(\mathrm{P}=0.0014)$.

For these reasons the authors concluded that overall survival with sorafenib was significantly higher than with sunitinib.

\section{Brivanib}

Brivanib is a tyrosine kinase inhibitor that shows selective inhibition of VEGFR and fibroblast growth factor receptor.

The antitumor activity of brivanib in patients with HCC was tested in three phase III studies.

In the BRISK-FL study [38] was tested in first-line. Median overall survival, time to progression and disease control rate were similar between sorafenib and brivanib.

In the BRISK-PS study [39] brivanib was tested in 395 patients with advanced HCC who progressed or were intolerant to sorafenib. Median overall survival was similar between brivanib and placebo arms ( 9.4 months for brivanib and 8.2 months for placebo, HR 0.89; $\mathrm{P}=.3307$ ), but brivanib was associated with a longer median time to progression than sorafenib (4.2 months for brivanib and 2.7 months for placebo HR: $0.56 \mathrm{P}<.001$ ).

The last (BRISK-APS) is an ongoing study [40] enrolling second-line patients from the Asian-Pacific region.

\section{Linifanib}

Linifanib is an orally active, potent and selective inhibitor of VEGFR and PDGFR.

A phase III trial [41] randomized 1,035 patients with median overall survival of 9.1 months in the linifanib arm and 9.8 months in the sorafenib arm. Linifanib and sorafenib resulted in similar overall surival associated with more toxicity for linifanib arms.

\section{Pazopanib}

Pazopanib is an orally inhibitor of VEGFR, PDGFR and c-Hit.

A phase I dose-escalating study of pazopanib [42] was conducted to determine the maximum tolerated dose, it was defined at $600 \mathrm{mg}$ once daily. No phase II trial has been programmed.

\section{Tivantinib}

Tivantinib is a selective inhibitor of MET.

In a phase II trial [43] 107 patients with unresectable HCC progressed after first-line treatment 
or were intolerant. Patients were randomized to receive either $360 \mathrm{mg}$ or $240 \mathrm{mg}$ of tivantinib twice daily or placebo.

Median OS was 7.2 months for patients treated with tivantinib compared with 3.8 months for patients treated with placebo (HR: $0.38, \mathrm{p}=0.01)$. Median time to progression was 2.9 months for patients treated with tivantinib compared 1.5 months for patients treated with placebo (HR 0:43, p=0.03). In this study MET level was predictive of time to progression and overall survival.

A global randomized phase III study comparing the clinical activity of tivantinib versus best supportive care in patients with hepatocellular carcinoma in secondline therapy will be presented at ASCO 2017 but a press release announced that the study did not meet the primary endpoint.

\section{Cabozantinib}

Cabozantinib is a dual MET/VEGFR-2 inhibitor. It was tested in second-line therapy for hepatocellular carcinoma in a phase II randomized study [44], with 41 patients enrolled, 4.4 months median PFS and 15.1 months median overall survival. A global randomized phase III study is ongoing.

\section{Ramucirumab}

A phase II study [45] of 42 patients with advanced hepatocellular carcinoma showed that ramucirumab in first-line produced a 50\% DCR and a median PFS of 4.3 months.

In the REACH study thee results show that the HR for overall survival was $0.866(p=0.1391)$; overall survival was 9.2 months and progression free survival was 2.8 months for the ramucirumab arm versus 7.6 months for overall surivival and 2.1 months for progression free survival in the placebo arm.

A subgroup analysis show that patients with high baseline alpha-fetoprotein $(\geq 400 \mathrm{ng} / \mathrm{mL})$ have a median OS of 7.8 months for ramucirumab versus 4.2 months for placebo, HR was $0.67(\mathrm{p}=0.0059)$ with [46].

This suggests that elevated baseline AFP may be a predictive marker for survival benefit to ramucirumab, and it is now the basis for a biomarker selected Phase III study (REACH-2) in the same setting.

\section{Cediranib}

Cediranib and vatalanib are oral inhibitors of VEGF receptor tyrosine kinase. A phase II study was published [47] with cediranib, but with no responses to the drug. Median OS was 5.8 months. No phase III trial has been programmed.

\section{Dovitinib}

Dovinitib is a potent tyrosine kinase inhibitor targeting at FGFR, VEGFR, PDGFR and c-kit.

In preclinical study dovinitib showed an activity in HCC [48].

A randomized phase II study [49] comparing the clinical activity of dovitinib versus sorafenib. In this trial dovitinib and sorafenib resulted in similar OS and TTP. No phase 3 trial has been planned.

\section{CONCLUSIONS}

Over the last decade, the progress in managing advanced liver cancers has been slow for three many reasons. First of all, we have probably failed in the planning phase of clinical trials. Published data show a wide heterogeneity in the study design, ethnicity of patients enrolled, underlying liver disease (HCV vs. HBV), grade of liver decompensation (Child A vs. Child B), BCLC stage (A vs. B vs. C often mixed in variable proportions), presence of patients with vascular invasion or metastatic disease, modality of sorafenib treatment (sequential vs. continuous vs. interrupted), type of TACE (conventional vs DEB-TACE), type of chemotherapy, number of drugs delivered (single agent vs. combination), dose of chemotherapy, use of embolizing materials, number of procedures administered, and schedule (ondemand vs. pre-planned). Consequently, the results of the studies are contrasting. Secondly, we lack effective drug. Thirdly, we did not properly plan effective strategies with treatment combinations or sequences. Combination therapy may provide clinical benefit for patients with HCC but subjects selection is imperative to avoid unacceptable toxicities or even harm (for example liver decompensation).

A better understanding of the biology of HCC, the variables that could predict response to sorafenib, and the mechanisms by which anti-angiogenic agents work in concert with conventional chemotherapeutic agents used in TACE, will be critical to design the definitive trial on the combination treatment. Post hoc analysis of the SHARP trial show that low baseline concentrations of angiopoietin-2 and VEGF-A were associated with better OS [50, 51]. Casadei Gardini et al and Scartozzi et al have studied the role of polymorphisms and response to sorafenib. This two study showed that VEGF-A, VEGF-C and $e N O S$ polymorphisms were independent factors of PFS and OS [52, 53].

We probably would have different therapeutic options in the first and second line of HCC treatment in the next five years, changing the scenario for this disease. As previously reported in the latest years for the kidney tumor we could have instead of few therapeutic options several active compounds. 
Many promising drugs in phase II studies failed in phase III trials. There are multiple reasons for these failures. The most important is the faulty study designs, in particular stratification at the time of randomization.

In the future we have to identify new meccanism of hepatocarcinogenesis to study new treatment approach.

\section{ACKNOWLEDGMENTS}

The authors would like to thank Ursula Elbling for editing the manuscript.

\section{CONFLICTS OF INTEREST}

The authors declare that there is no conflicts of interest regarding the publication of this article.

\section{REFERENCES}

1. Lo CM, Ngan H, Tso WK, Liu CL, Lam CM, Poon RT, Fan ST, Wong J. Randomized controlled trial of transarterial lipiodol chemoembolization for unresectable hepatocellular carcinoma. Hepatology. 2002; 35:1164-1171.

2. Bruix J, Llovet JM, Castells A, Montana X, Bru C, Ayuso MC, Vilana R, Rodés J. Transarterial embolization versus symptomatic treatment in patients with advanced hepatocellular carcinoma: results of a randomized, controlled trial in a single institution. Hepatology. 1998; 27:1578-1583.

3. Takayasu K, Arii S, Ikai I, Kudo M, Matsuyama Y, Kojiro M, Makuuchi M; Liver Cancer Study Group of Japan. Overall survival after transarterial lipiodol infusion chemotherapy with or without embolization for unresectable hepatocellular carcinoma: propensity score analysis. Am J Roentgenol. 2010; 194:830-837.

4. Luo J, Guo RP, Lai EC, Zhang YJ, Lau WY, Chen MS, Shi M. Transarterial chemoembolization for unresectable hepatocellular carcinoma with portal vein tumor thrombosis: a prospective comparative study. Ann Surg Oncol. 2011; 18:413-420.

5. Chung GE, Lee JH, Kim HY, Kim HY, Hwang SY, Kim JS, Chung JW, Yoon JH, Lee HS, Kim YJ. Transarterial chemoembolization can be safely performed in patients with hepatocellular carcinoma invading the main portal vein and may improve the overall survival. Radiology. 2011; 258:627-634.

6. Lee S, Kim BK, Kim SU, Park Y, Chang S, Park JY, Kim DY, Ahn SH, Chon CY, Han KH. Efficacy of sorafenib monotherapy versus sorafenib-based loco-regional treatments in advanced hepatocellular carcinoma. PLoS One. 2013; 8:e77240. https://doi.org/10.1371/journal. pone. 0077240 .
7. Alba E, Valls C, Dominguez J, Martinez L, Escalante E, Lladó L, Serrano T. Transcatheter arterial chemoembolization in patients with hepatocellular carcinoma on the waiting list for orthotopic liver transplantation. AJR Am J Roentgenol. 2008; 190:1341-1348.

8. Bruix J, Sherman M; American Association for the Study of Liver Diseases. Management of hepatocellular carcinoma: an update. Hepatology. 2011; 53:1020-1022.

9. Shim JH, Park JW, Kim JH, An M, Kong SY, Nam BH, Choi JI, Kim HB, Lee WJ, Kim CM. Association between increment of serum VEGF level and prognosis after transcatheter arterial chemoembolization in hepatocellular carcinoma patients. Cancer Sci. 2008; 99:2037-2044.

10. Sergio A, Cristofori C, Cardin R, Pivetta G, Ragazzi R. Baldan A, Girardi L, Cillo U, Burra P, Giacomin A, Farinati F. Transcatheter arterial chemoembolization (TACE) in hepatocellular carcinoma (HCC): the role of angiogenesis and invasiveness. Am J Gastroenterol. 2008; 103:914-921.

11. Llovet JM, Ricci S, Mazzaferro V, Hilgard P, Gane E, Blanc JF, de Oliveira AC, Santoro A, Raoul JL, Forner A, Schwartz M, Porta C, Zeuzem S, et al. Sorafenib in advanced hepatocellular carcinoma. N Engl J Med. 2008; 359:378-390.

12. Cheng AL, Kang YK, Chen Z, Tsao CJ, Qin S, Kim JS, Luo R, Feng J, Ye S, Yang TS, Xu J, Sun Y, Liang H, et al. Efficacy and safety of sorafenib in patients in the AsiaPacific region with advanced hepatocellular carcinoma: a phase III randomised, double-blind, placebo-controlled trial. Lancet Oncol. 2009; 10:25-34.

13. Casadei Gardini A, Marisi G, Scarpi E, Scartozzi M, Faloppi L, Silvestris N, Masi G, Vivaldi C, Brunetti O, Tamberi S, Foschi FG, Tamburini E, Tenti E, et al. Effects of metformin on clinical outcome in diabetic patients with advanced HCC receiving sorafenib. Expert Opin Pharmacother. 2015; 16:2719-2725.

14. Casadei Gardini A, Scarpi M, Marisi G, Foschi FG, Donati G, Giampalma E, Faloppi L, Scartozzi M, Silvestris N, Bisulli M, Corbelli J, Gardini A, La Barba G, et al. Early onset of hypertension and serum electrolyte changes as potential predictive factors of activity in advanced HCC patients treated with sorafenib: results from a retrospective analysis of the HCC-AVR group. Oncotarget. 2016; 7:15243-51. https://doi.org/10.18632/oncotarget.7444.

15. Scartozzi M, Faloppi L, Svegliati-Baroni G, Loretelli C, Piscaglia F, Iavarone M, Toniutto P, Fava G, De Minicis S, Mandolesi A, Bianconi M, Giampieri R, Granito A, et al. VEGF and VEGFR genotyping in the prediction of clinical outcome for HCC patients receiving sorafenib: the ALICE-1 study. Int J Cancer. 2014; 135:1247-1256.

16. Gnoni A, Santini D, Scartozzi M, Russo A, Licchetta A, Palmieri V, Lupo L, Faloppi L, Palasciano G, Memeo V, Angarano G, Brunetti O, Guarini A, et al. Hepatocellular carcinoma treatment over sorafenib: epigenetics, 
microRNAs and microenvironment. Is there a light at the end of the tunnel? Expert Opin Ther Targets. 2015; 19:1623-1635.

17. Chu JS, Ge FJ, Zhang B, Wang Y, Silvestris N, Liu LJ, Zhao $\mathrm{CH}$, Lin L, Brunetti AE, Fu YL, Wang J, Paradiso A, Xu JM. Expression and prognostic value of VEGFR-2, PDGFR- $\beta$, and c-Met in advanced hepatocellular carcinoma. Exp Clin Cancer Res. 2013; 32:16.

18. Strebel BM, Dufour JF. Combined approach to hepatocellular carcinoma: a new treatment concept for unresectable disease. Expert Rev Anticancer Ther. 2008; 8:1743-1749.

19. Lencioni R, Llovet JM, Han G, Tak WY, Yang J, Guglielmi A, Paik SW, Reig M, Kim do Y, Chau GY, Luca A, del Arbol LR, Leberre MA, et al. Bruix Sorafenib or placebo plus TACE with doxorubicin-eluting beads for intermediate stage HCC: the SPACE trial. J Hepatol. 2016; 64:1090 1098. https://doi.org/10.1016/j.jhep.2016.01.012.

20. Kudo M, Imanaka K, Chida N, Nakachi K, Tak WY, Takayama T, Yoon JH, Hori T, Kumada H, Hayashi N, Kaneko S, Tsubouchi H, Suh DJ, et al. Phase III study of sorafenib after transarterial chemoembolization in Japanese and Korean patients with unresectable hepatocellular carcinoma. Eur J Cancer. 2011; 47:2117-2127.

21. Sansonno D, Lauletta G, Russi S, Conteduca V, Sansonno L, Dammacco F. Transarterial chemoembolization plus sorafenib: a sequential therapeutic scheme for HCV-related intermediate-stage hepatocellular carcinoma: a randomized clinical yrial. Oncologist. 2012; 17:359-366.

22. Hoffmann K, Ganten T, Gotthardtp D, Radeleff B, Settmacher U, Kollmar O, Nadalin S, KarapanagiotouSchenkel I, von Kalle C, Jäger D, Büchler MW, Schemmer P. Impact of neo-adjuvant Sorafenib treatment on liver transplantation in HCC patients - a prospective, randomized, double-blind, phase III trial. BMC Cancer. 2015; 15:392. https://doi.org/10.1186/s12885-015-1373-z.

23. Zeng J, Lv L, Mei ZC. Efficacy and safety of transarterial chemoembolization plus sorafenib for early or intermediate stage hepatocellular carcinoma: A systematic review and meta-analysis of randomized controlled trials. Clin Res Hepatol Gastroenterol. 2016; 40:688-697. https://doi. org/10.1016/j.clinre.2016.04.006.

24. Chao YL, Yoon J, Li C. START: Study in Asia of the combination of TACE (transcatheter arterial chemoembolization) with sorafenib in patients with hepatocellular carcinoma trial. ILCA Annual conference. 2011; 17.

25. Erhardt AK, Dollinger MM, Schott E, Wege H, Bitzer M, Gog C, Lammert F, Schuchmann M, Walter C, Blondin D, Ohmann C, Häussinger D. TACE plus sorafenib for the treatment of hepatocellular carcinoma: Final results of the multicenter SOCRATES trial. Cancer Chemother Pharmacol. 2014; 74:947-954.

26. Park JW, Koh YH, Kim HB, Kim HY, An S, Choi JI, Woo $\mathrm{SM}$, Nam BH. Phase II study of concurrent transarterial chemoembolization and sorafenib in patients with unresectable hepatocellular carcinoma. J Hepatol. 2012; 56:1336-1342.

27. Pawlik TM, Reyes DK, Cosgrove D, Kamel IR, Bhagat N, Geschwind JF. Phase II trial of sorafenib combined with concurrent transarterial chemoembolization with drugeluting beads for hepatocellular carcinoma. J Clin Oncol. 2011; 29:3960-3967.

28. clinicaltrials.gov NCT01906216.

29. clinicaltrials.gov NCT01004978.

30. ClinicalTrials.gov identifier NCT01004978.

31. clinicaltrials.gov NCT 01833299.

32. Bruix J, Merle P, Granito A, Huang YH, Bodoky G, Yokosuka O, Rosmorduc O, Breder V, Gerolami R, Masi G, Ross Paul J, Qin S, Song T, et al. Efficacy and safety of regorafenib versus placebo in patients with hepatocellular carcinoma (HCC) progressing on sorafenib: results of the international, randomized phase 3 RESORCE trial. Ann Oncol. 2016; 27:ii140-ii141. https://doi.org/10.1093/ annonc/mdw237.03.

33. Siegel AB, Cohen EI, Ocean A, Lehrer D, Goldenberg A, Knox JJ, Chen H, Clark-Garvey S, Weinberg A, Mandeli J, Christos P, Mazumdar M, Popa E, et al. Phase II trial evaluating the clinical and biologic effects of bevacizumab in unresectable hepatocellular carcinoma. J Clin Oncol. 2008; 26:2992-2998.

34. Kaseb AO, Garrett-Mayer E, Morris JS, Xiao L, Lin E, Onicescu G, Hassan MM, Hassabo HM, Iwasaki M, Deaton FL, Abbruzzese JL, Thomas MB. Efficacy of bevacizumab plus erlotinib for advanced hepatocellular carcinoma and predictors of outcome: final results of a phase II trial. Oncology. 2012; 82:67-74.

35. Thomas MB, Morris JS, Chadha R, Iwasaki M, Kaur H, Lin E, Kaseb A, Glover K, Davila M, Abbruzzese J. Phase II trial of the combination of bevacizumab and erlotinib in patients who haveadvanced hepatocellular carcinoma. J Clin Oncol. 2009; 27:843-850.

36. Philip PA, Mahoney MR, Holen KD, Northfelt DW, Pitot HC, Picus J, Flynn PJ, Erlichman C. Phase 2 study of bevacizumab plus erlotinib in patients with advanced hepatocellular cancer. Cancer. 2012; 118:2424-2430.

37. Cheng AL, Kang YK, Lin DY, Park JW, Kudo M, Qin S, Chung HC, Song X, Xu J, Poggi G, Omata M, Pitman Lowenthal S, Lanzalone S, et al. Sunitinib versus sorafenib in advanced hepatocellular cancer: results of a randomized phase III trial. J Clin Oncol. 2013; 31:4067-4075.

38. Johnson PJ, Qin S, Park JW, Poon RT, Raoul JL, Philip PA, Hsu CH, Hu TH, Heo J, Xu J, Lu L, Chao Y, Boucher E, et al. Brivanib versus sorafenib as first-line therapy in patients with unresectable, advanced hepatocellular carcinoma: results from the randomized phase III BRISK-FL study. J Clin Oncol. 2013; 31:3517-3524.

39. Llovet JM, Decaens T, Raoul JL, Boucher E, Kudo M, Chang C, Kang YK, Assenat E, Lim HY, Boige V, Mathurin 
P, Fartoux L, Lin DY, et al. Brivanib in patients with advanced hepatocellular carcinoma who were intolerant to sorafenib or for whom sorafenib failed: results from the randomized phase III BRISK-PS study. J Clin Oncol. 2013; 31:3509-3516.

40. Comparison of Brivanib and Best Supportive Care (BSC) With Placebo and BSC for Treatment of Liver Cancer in Asian Patients Who Have Failed Sorafenib Treatment (BRISK-APS). ClinicalTrials.gov Identifier: NCT01108705.

41. Cainap C, Qin S, Huang WT, Chung IJ, Pan H, Cheng Y, Kudo M, Kang YK, Chen PJ, Toh HC, Gorbunova V, Eskens F, Qian J, et al. Phase III trial of linifanib versus sorafenib in patients with advanced hepatocellular carcinoma (HCC). J Clin Oncol. 2015; 33:172-179.

42. Yau T, Chen PJ, Chan P, Curtis CM, Murphy PS, Suttle AB, Gauvin J, Hodge JP, Dar MM, Poon RT. Phase I dosefinding study of pazopanib in hepatocellular carcinoma: evaluation of early efficacy, pharmacokinetics, and pharmacodynamics. Clin Cancer Res. 2011; 17:6914-6923.

43. Santoro A, Rimassa L, Borbath I, Daniele B, Salvagni S, Van Laethem JL, Van Vlierberghe H, Trojan J, Kolligs FT, Weiss A, Miles S, Gasbarrini A, Lencioni M, et al. Tivantinib for second-line treatment of advanced hepatocellular carcinoma: a randomised, placebo-controlled phase 2 study. Lancet Oncol. 2013; 14:55-63.

44. Verslype C, Cohn AL, Kelley RK, Yang TS, Su WC, Ramies DA, Lee Y, Shen X, Cutsem EV. Activity of cabozantinib (XL184) in hepatocellular crcinoma: results from a randomized phase II discontinuation study. Proc Am Soc Clin Oncol. 2012; 30:4007.

45. Zhu AX, Finn RS, Mulcahy MF, Gurtler JS, Sun W, Schwartz JD, Rojas P, Dontabhaktuni A, Youssoufian H, Stuart KE. A phase II study of ramucirumab as first-line monotherapy in patients (pts) with advanced hepatocellular carcinoma (HCC). J Clin Oncol. 2010; 28:4083.

46. Zhu AX, Ryoo BY, Yen CJ, Kudo M, Poon RT, Pastorelli D, Blanc JF, Chung HC, Baron AD, Pfiffer TE, Okusaka T, Kubackova K, Trojan J, et al. Ramucirumab (RAM) as second-line treatment in patients (pts) with advanced hepatocellular carcinoma (HCC): analysis of patients with elevated $\alpha$-fetoprotein (AFP) from the randomized phase III REACH study. J Clin Oncol. 2015; 33:232.
47. Alberts SR, Fitch TR, Kim GP, Morlan BW, Dakhil SR, Gross HM, Nair S. Cediranib (AZD2171) in patients with advanced hepatocellular carcinoma: a phase II North Central Cancer Treatment Group Clinical Trial. Am J Clin Oncol. 2012; 35: 329-333.

48. Huynh H, Chow PK, Tai WM, Choo SP, Chung AY, Ong HS, Soo KC, Ong R, Linnartz R, Shi MM. Dovitinib demonstrates antitumor and antimetastatic activities in xenograft models of hepatocellular carcinoma. J Hepatol. 2012; 56:595-601. https://doi.org/10.1016/j. jhep.2011.09.017.

49. Cheng AL, Thongprasert S, Lim HY, Sukeepaisarnjaroen W, Yang TS, Wu CC, Chao Y, Chan SL, Kudo M, Ikeda M, Kang YK, Pan H, Numata K, et al. Randomized, Open-Label Phase 2 study comparing frontline dovitinib versus sorafenib in patients with advanced hepatocellular carcinoma. Hepatology. 2016; 64:774-784.

50. Llovet JM, Pena CE, Lathia CD, Shan M, Meinhardt G, Bruix J; SHARP Investigators Study Group. Plasma biomarkers as predictors of outcome in patients with advanced hepatocellular carcinoma. Clin Cancer Res. 2012; 18:2290-2300.

51. Miyahara K, Nouso K, Tomoda T, Kobayashi S, Hagihara H, Kuwaki K, Toshimori J, Onishi H, Ikeda F, Miyake Y, Nakamura S, Shiraha H, Takaki A, et al. Predicting the treatment effect of sorafenib using serum angiogenesis markers in patients with hepatocellular carcinoma. J Gastroenterol Hepatol. 2011; 26:1604-1611.

52. Casadei Gardini A, Marisi G, Faloppi L, Scarpi E, Giuseppe Foschi F, Iavarone M, Lauletta G, Corbelli J, Valgiusti M, Facchetti F, Corte C, Maria Neri L, Tamberi S, et al. eNOS polymorphisms and clinical outcome in advanced HCC patients receiving sorafenib: nal results of the ePHAS study. Oncotarget. 2016; 7:27988-27999. https://doi. org/10.18632/oncotarget.8569.

53. Scartozzi M, Faloppi L, Svegliati-Baroni G, Loretelli C, Piscaglia F, Iavarone M, Toniutto P, Fava G, De Minicis S, Mandolesi A, Bianconi M, Giampieri R, Granito A, et al. VEGF and VEGFR genotyping in the prediction of clinical outcome for HCC patients receiving sorafenib: the ALICE-1 study. Int J Cancer. 2014; 135:1247-1256. 